\title{
LIQUID PHASE EPITAXIAL GROWTH OF THICK GARNET FILMS —"PERFECTNESS" OF CRYSTAL QUALITY-
}

\author{
T. HIBIYA \\ Fundamental Research Laboratories, NEC Corporation, Miyamae-ku, Kawasaki 213, Japan
}

\begin{abstract}
"Perfectness of crystal quality" of thick liquid phase epitaxial magneto-optic garnets is discussed. A phase diagram should be carefully checked prior to LPE growth to keep melt compositions in the primary phase of the garnet. Crystallographic orientation of the utilized substrates, as well as melt composion, is an important factor in obtaining inclusion-free garnet layers with uniform thickness, since a growth mechanism which depends on crystallographic orientation plays an important role in controlling the surface morphology of garnet layers; a $\{111\}$ wafer orientation and melts rich in $\mathrm{B}_{2} \mathrm{O}_{3}$ should be utilized. $\AA$ flux residue problem on the surface of Bi-substituted garnets is explained by a wetting phenomenon between the flux and garnet surface, whose surface tension is also dependent on crystallographic orientation. Flux residue is observed for Bi-substituted garnets, not only on $\{100\}$ but also on $\{111\}$. Optical absorption is discussed in the light of a kinetic effect on impurity incorporation. Optical absorption loss is also dependent on melt supercooling temperature and wafer orientation; the $\{110\}-29^{\circ}$-off film, i.e. $\{211\}-1^{\circ}$-off film, shows an anomalously large optical absorption.
\end{abstract}

\section{INTRODUCTION}

The application of thick liquid-phase epitaxial (LPE) garnet films to a magneto-optical device such as an optical isolator has been proposed. [1],[2] In this report the technology necessary to prepare thick LPE garnet films of optical device quality is described from the viewpoint of crystal "perfectness"; discussions on the phase diagram, inclusion due to spontaneous nucleation, surface morphology, flux residue after growth and optical absorption are given mainly in the light of the crystallographic oriention of the substrates utilized.

\section{PHASE DIAGRAM AND LPE GROWTH}

When a flux-method is utilized for crystal growth, a flux composition must be in the primary phase region for crystals to be obtained. However, thick LPE YIG films once grown on GGG $\left(\mathrm{Gd}_{3} \mathrm{Ga}_{5} \mathrm{O}_{12}\right)$ substrates from $\mathrm{R}_{1}=\left[\mathrm{Fe}_{2} \mathrm{O}_{3}\right] /\left[\mathrm{Y}_{2} \mathrm{O}_{3}\right]=14.0$ and $\mathrm{R}_{3}=[\mathrm{PbO}] /\left[\mathrm{B}_{2} \mathrm{O}_{3}\right]=15.6$ melts, within the garnet primary phase region reported, were found to be dissolved after a prolonged time dipping process, while spontaneous nucleation of yttrium orthoferrite $\left(\mathrm{YFeO}_{3}\right)$ took place, [3] where the $R$-parameters are molar ratios of melt compositions defined by Blank and Nielsen. [4] Nevertheless, thin films $(\sim 15 \mu \mathrm{m})$ were reproducibly obtained by short time dipping from the same melt without orthoferrite nucleation (see Fig. 1).

This phenomenon was mainly explained by a metastable behavior of the melt; the melt was supersaturated both with garnet and orthoferrite phases. The difference in the Gibbs free energy change associated with nucleation is described in Eq.(1),

$$
\Delta \mathrm{G}=4 \pi r^{2} \gamma+4 / 3 \pi r^{3} \Delta G_{v}
$$

where $r$ is the radius of the embryo. $\gamma$ is the interfacial energy of the solid phase and has a positive value. $\Delta \mathrm{Gv}$ is the difference in the Gibbs free energy per unit volume between the solid and the liquid phase, and has a negative value below the liquidus temperature. The Garnet phase can appear as soon as the sign of the free energy change for nucleation becomes minus, since the existence of the substrate crystal makes the interfacial energy term of the free energy change for nucleation almost zero, but this is not the case for orthoferrite. The phenomenon observed should also be attributed to the fact that the Gibbs free energies of formation per mole of $\mathrm{Fe}^{3+}$ for $\mathrm{YFeO}_{3}$ and YIG have almost the same values: $-250.2 \mathrm{~kJ} / \mathrm{mol} \mathrm{Fe}^{3+}$ for $\mathrm{YFeO}_{3}$ and -241.7 $\mathrm{kJ} / \mathrm{mol} \mathrm{Fe}^{3+}$ for YIG, respectively. [5]

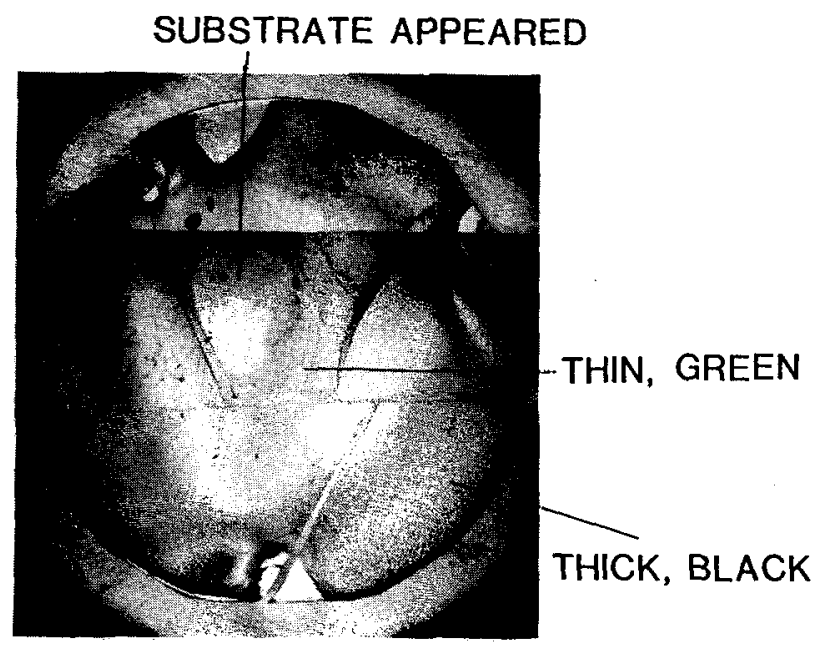

$23 \mathrm{~mm}$ DIA

Fig.1. Thick YIG film grown on the GGG substrate from the orthoferrite primary phase melt. The central part of the thick film was dissolved and the GGG substrate appeared. The wafer was broken during the cooling process. Two photographs were combined to cover the whole wafer. [3]. 


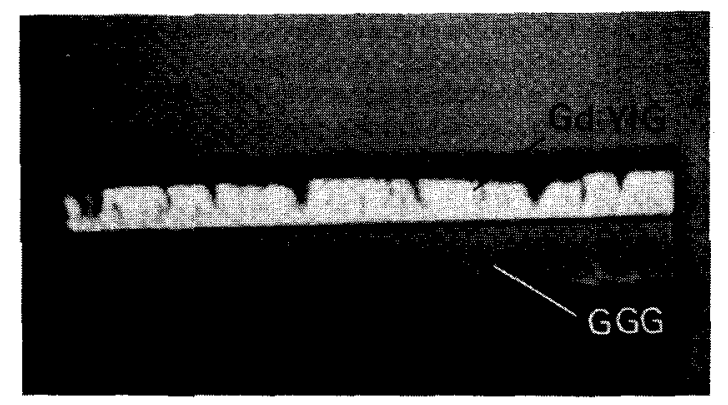

Fig.2. Infrared TV image of a $200 \mu \mathrm{m}$ thick $\mathrm{Gd}_{0.2} \mathrm{Y}_{2.8} \mathrm{Fe}_{5} \mathrm{O}_{12}$ garnet film grown on a GGG substrate. Incident light was launched parallel to the film surface. The funnel-shaped dark portions correspond to light absorption due to included garnet microcrystals and their surroundings. [6]
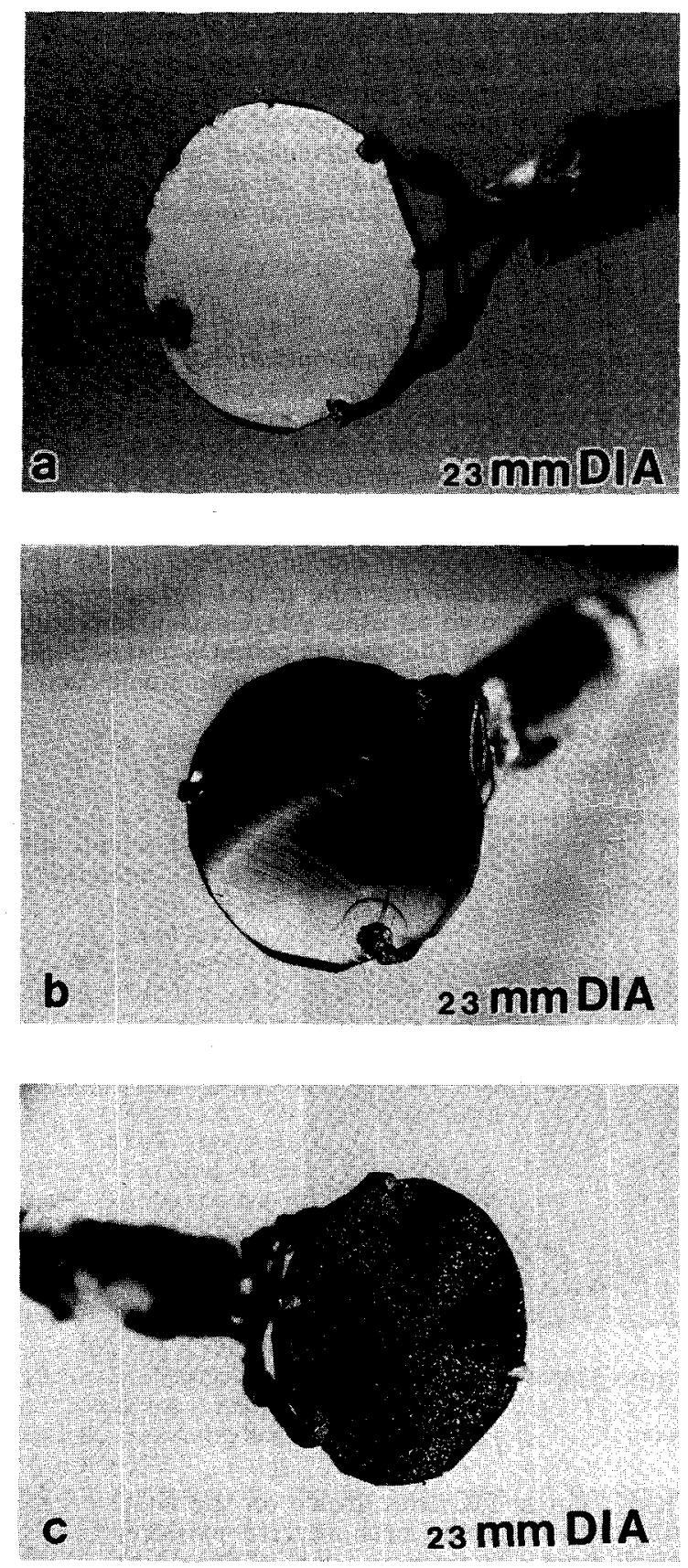

Fig.3. Three types of surface morphology for thick $\{111\}$ garnet LPE films: (a) 168
Using the revised phase diagram for the LPE growth of garnet films, thick $\mathrm{Gd}_{0.2} \mathrm{Y}_{2.8} \mathrm{Fe}_{5} \mathrm{O}_{12}$ films are reproducibly obtained.

\section{INCLUSION}

Control of the supercooling is important for thick garnet film preparation. For thin film preparation, e.g. thin films for bubble domain applications, the flux melt can endure a high degree of supercooling, since the growth time is quite short (10 minutes maximum). However, supercooling was sometimes broken for thick film preparation, since it takes 20 hours or more. When the thick film was prepared under $40^{\circ} \mathrm{C}$ supercooling, spontaneous garnet phase nucleation took place. Garnet microcrystals were included into thick films, as shown in Fig. 2: an infrared TV image for a 200 um thick $\mathrm{Gd}_{0.2} \mathrm{Y}_{2.8} \mathrm{Fe}_{5} \mathrm{O}_{12}$ garnet film grown on a GGG substrate. Incident light was launched parallel to the film surface. The Funnel-shaped dark portions correspond to light absorption attributed to included microcrystals and their surroundings. [6] In order to avoid garnet phase spontaneous nucleation, as small a degree of supercooling as possible is required.

\section{SUBSTRATE ORIENTATION AND SURFACE MORPHOLOGY}

Substrate orientation is an important factor in obtaining thick device quality garnet films, since the surface morphology is affected by the growth mechanism, which is quite dependent on growth direction. In this section, the surface morphologies of $\{111\},\{110\}$ and misoriented $\{110\}$ thick garnet films are described. Employing a wafer orientation of $\{111\}$ and melts rich in $\mathrm{B}_{2} \mathrm{O}_{3}, 300 \mu \mathrm{m}$ thick garnet layers without flux-inclusion were obtained.

\subsection{Growth on $\{111\}$ substrates}

Surface morphologies for $\{111\}$ films are classified into three types; they are "mirror", "striation" and "swirl" as shown in Fig.3. [7] The surface morphology of $\left\{\begin{array}{ll}11 & 1\end{array}\right\}$ growth was found to be dependent on film thickness, growth temperature and melt $\mathrm{PbO} / \mathrm{B}_{2} \mathrm{O}_{3}$ ratio, as shown in Fig. 4. [7],[8]

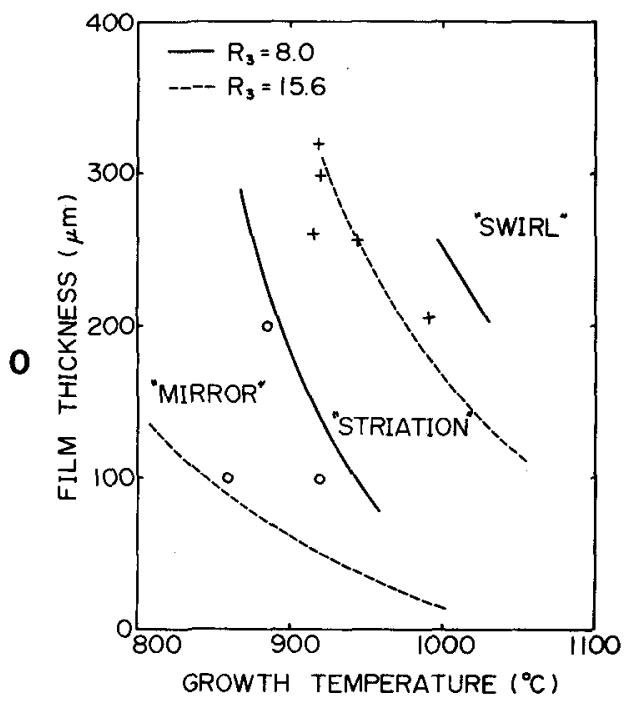

Fig.4. Morphological map for the $\{111\}$ LPE garnet films from the $R_{3}=8.0$ melts: (-) morphological boundaries for the $\mathrm{R}_{3}=8.0$ melts. Morphological boundaries for the $R_{3}=15.6$ melts are also superimposed: $(--)$. [8] 
Since a "swirl" is accompanied by flux inclusion as shown in Fig. 5, the surface morphology must be "mirror" or "striation". Employment of melts rich in $\mathrm{B}_{2} \mathrm{O}_{3}$ improved surface morphology; thick films grown from melts rich in $\mathrm{B}_{2} \mathrm{O}_{3}$ showed milder surface morphology than those grown from melts poor in $\mathrm{B}_{2} \mathrm{O}_{3}$. Inclusion-free $\mathrm{Gd}_{0.2} \mathrm{Y}_{2.8} \mathrm{Fe}_{5} \mathrm{O}_{12}$ films over 300 $\mu \mathrm{m}$ thick were obtained on $\{111\}$ GGG substrates.

For the "striation" from $\mathrm{B}_{2} \mathrm{O}_{3}$-rich melts the $\{110\}$ or $\{211\}$ facet did not appear, as shown in Fig.6, while the "swirl" consists of $\{110\}$ and $\{211\}$ facets, where layer by layer growth takes place on the facets. On the other hand, the $\{111\}$ is not a natural surface of the garnet system but is an atomically rough "kinked" surface, where adhesive growth takes place. The employment of melts rich in $\mathrm{B}_{2} \mathrm{O}_{3}$ would make the melt viscosity larger and keep the growth mechanism to adhesive growth by a "diffusion regime". Addition of $\mathrm{B}_{2} \mathrm{O}_{3}$ would also suppress pits whose surfaces consist of low index planes, such as $\{110\}$ and $\{211\}$. One of the origins for pit generation has been reported to be the adhesion of metallic platinum flakes on the solid/liquid interface. [9],[10]

The different origin for pit generation was also found; etch-pits of grown-in dislocation of the substrates revealed by a phosphoric acid are replicated to LPE films and cause a development of a "swirl" pattern. [11]

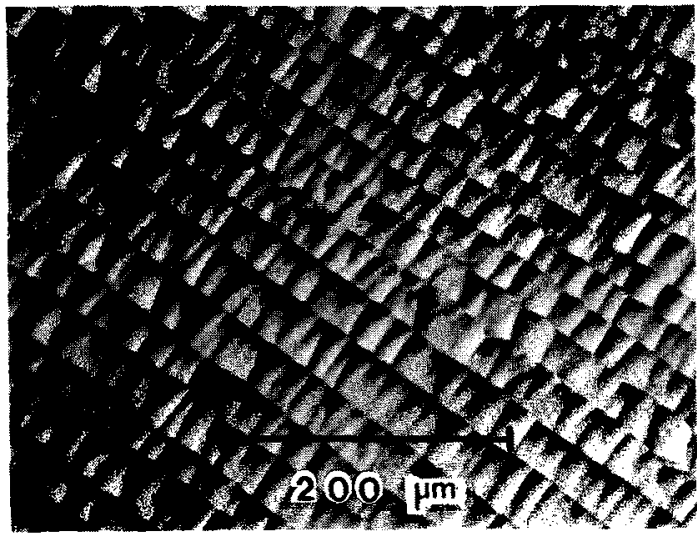

Fig.6. Surface morphology classified as "striation" : thick films from the $R_{3}=8.0$ melt. [8]

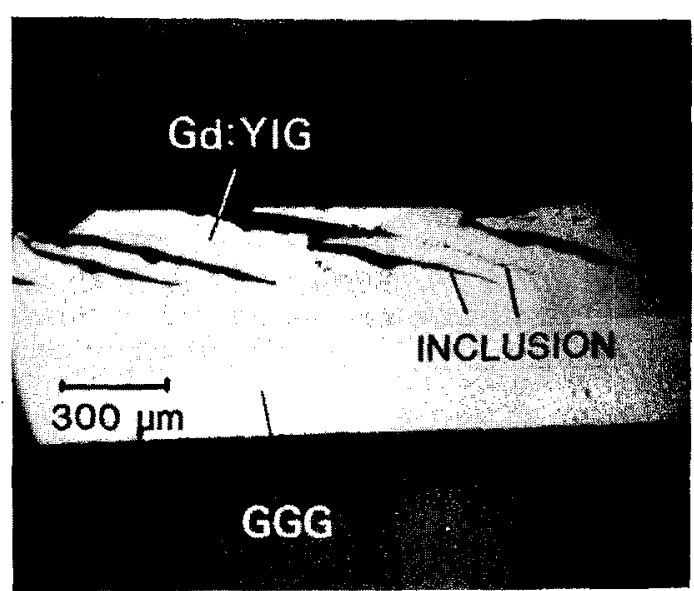

Fig.5. Flux inclusion observed for the thick \{111\} film whose surface morphology was classified as "swirl"; sectioned almost parallel to the melt flow direction. The eaves were developed downstream and flux was included beneath the eaves. [7]

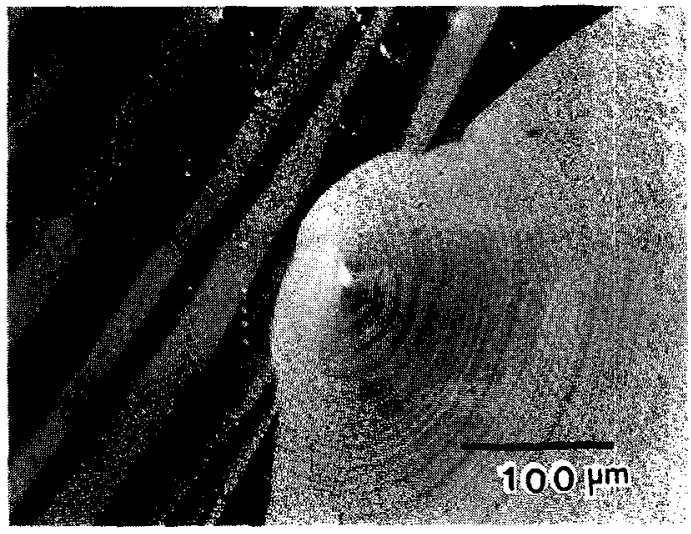

Fig.7. Hillocks and macrosteps observed for a thick $\{110\} \mathrm{Gd}_{2.71} \mathrm{Bi}_{0.29} \mathrm{Fe}_{5} \mathrm{O}_{12}$ film. [12]

FLUX
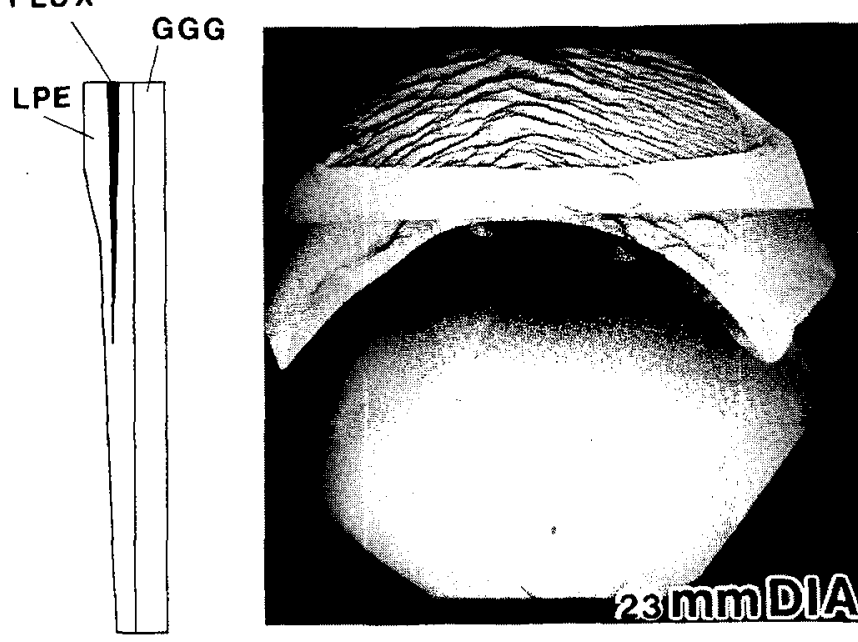

Fig.8. Thick $\{110\}-1^{\circ}$-off $\mathrm{Gd}_{0.2} \mathrm{Y}_{2.8} \mathrm{Fe}_{5} \mathrm{O}_{12}$ film. The major part of the surface was flat but a wedge-shaped flux inclusion was observed. Two photographs were combined to cover the whole wafer.

\subsection{Growth on $\{110\}$ and misoriented $-\{110\}$ substrate}

As shown in Fig.7, for LPE growth on the $\{110\}$ substrates, hillocks and macrosteps were developed due to spiral growth, and film thickness was not equal all over the wafer. [12] A difference in the lattice parameter from layer to layer of the growth unit would deteriorate the extinction ratio, when a light beam is launched parallel to the wafer surface.

When $\{110\}-1^{\circ}$-off substrates were utilized, hillock generation was suppressed to some extent. However, flux inclusion took place due to a different mode from that observed for "swirl" of $\{111\}$ growth. Figure 8 shows a top view of a $\{110\}-1^{\circ}$-off $\mathrm{Gd}_{0.2} \mathrm{Y}_{2.8} \mathrm{Fe}_{5} \mathrm{O}_{12}$ film. The major part of the surface was flat but a wedge-shaped flux inclusion was observed. This is due to generation of the $\{110\}$ eave. The growth direction was changed from $<110>-1^{\circ}$-off to $\langle 110\rangle$. At the upper part of Fig. 8 giant macrosteps were observed. 


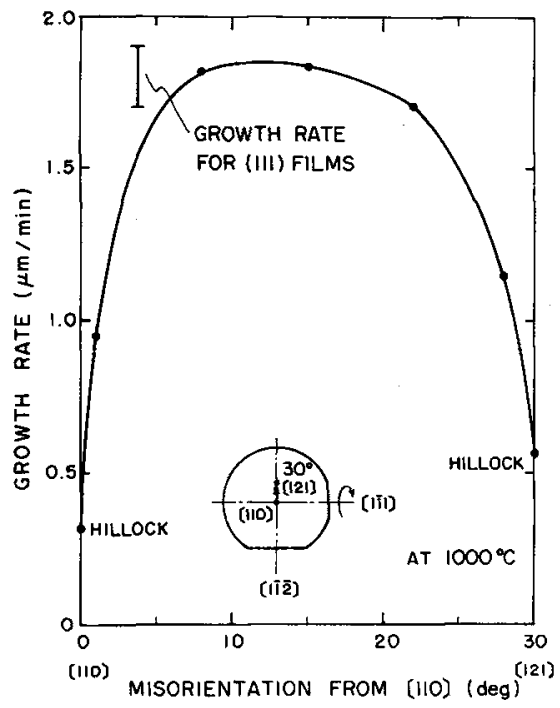

Fig.9. Growth rate of $\mathrm{Gd}_{0.2} \mathrm{Y}_{2.8} \mathrm{Fe}_{5} \mathrm{O}_{12}$ film as a function of misorientation angle of $\mathrm{Gd}_{3} \mathrm{Ga}_{5} \mathrm{O}_{12}$ from $\{110\}$. The growth rate on a $\{111\}$ substrate is also superimposed, although [111] does not appear on this abscissa.
For growth of a thick $\mathrm{Gd}_{0.2} \mathrm{Y}_{2.8} \mathrm{Fe}_{5} \mathrm{O}_{12}$ film on the $\{110\}-8^{\circ}$-off substrate, "swirl" appeared. The growth mechanism would be more similar to that on $\{111\}$ substrates than that on $\{110\}$ substrates. This was supported by a growth orientation dependence of grwoth rate, as shown in Fig. 8, since growth rate is directly controlled by a growth mechanism. However, when observed under a microscope, scale- or ladderlike macrosteps were observed, depending on the portion of the wafer observed, as shown in Figs. 10a and $10 \mathrm{~b}$.

Thick films grown on $\{110\}$ or misoriented $\{110\}$ substrates could not be used for practical devices because of flux inclusion, despite their rather uniform thickness than that of $\{111\}$.
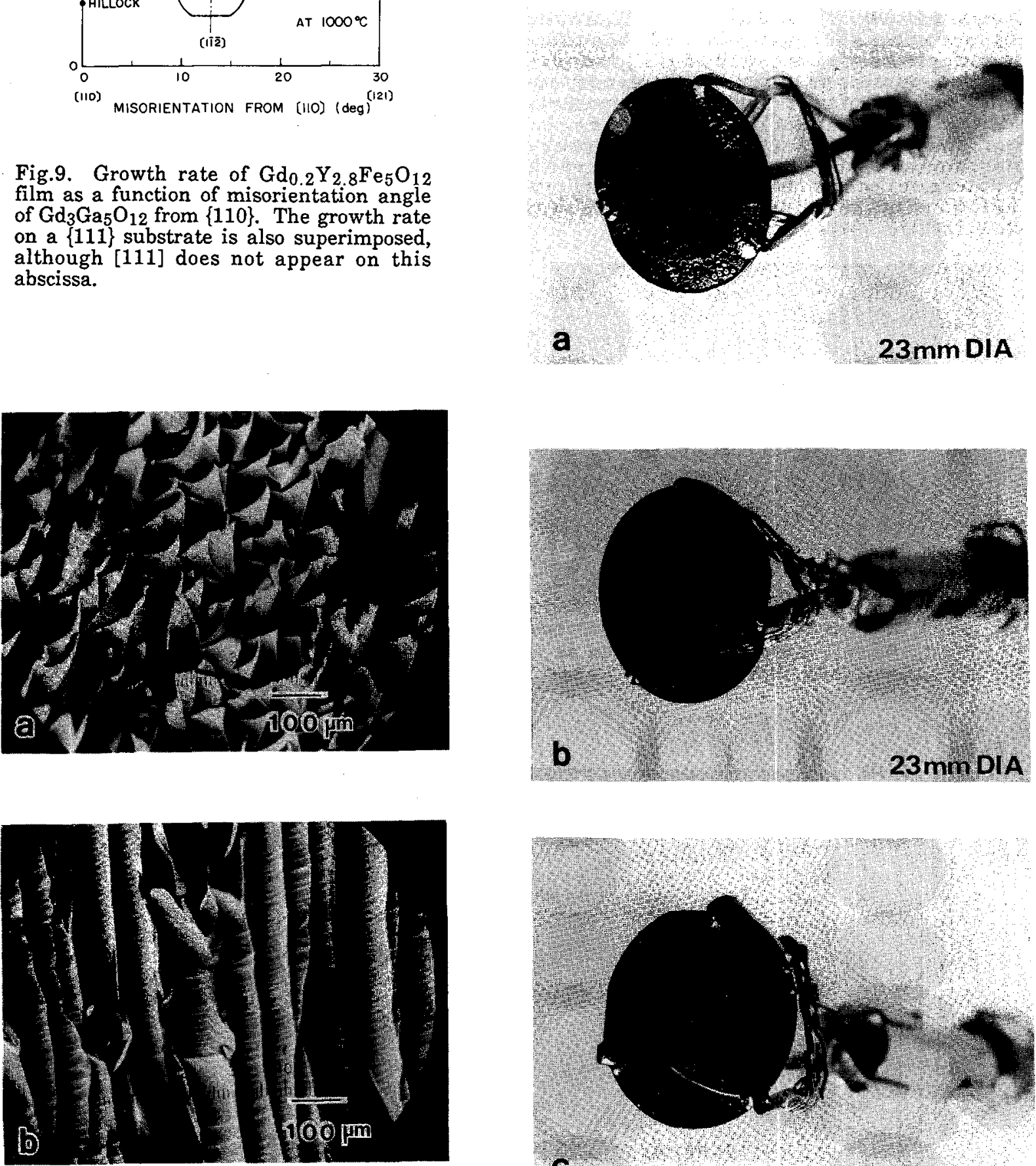

Fig.10. Surface morphology for $200 \mu \mathrm{m}$ thick $\{110\}-8^{\circ}$ off $\mathrm{Gd}_{0.2} \mathrm{Y}_{2.8} \mathrm{Fe}_{5} \mathrm{O}_{12}$ film: (a) scale-like macrosteps and (b) ladder-like macrosteps.

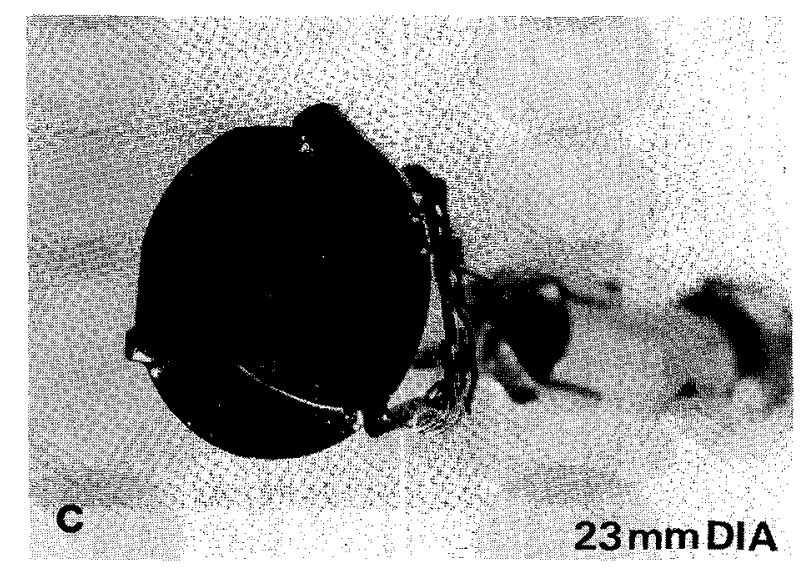

Fig.11. Flux residue after spinning off the flux on the surfaces of $(\mathrm{LuBi})_{3} \mathrm{Fe}_{5} \mathrm{O}_{12}$ films with different orientations: (a) $\{100\}$; (b) $\{111\} ;$; (c) $\{110\}$. [16] 


\section{FLUX RESIDUE AFTER GROWTH}

For Bi-substituted garnet films, flux residue after growth, even after high speed spinning-off for flux removal, has been reported. [13],[14] Flux residue can be explained by wetting between flux melts and garnet surfaces; a spreading type of wetting takes place, as shown in Eq.(2), [15]

$$
\gamma_{\mathrm{s}}>\gamma_{\mathrm{i}}+\gamma_{\mathrm{l}}
$$

where $\gamma_{\mathrm{s}}$ and $\gamma_{1}$ are the surface tensions for the solid and liquid phases, respectively. $\gamma_{i}$ is the interfacial tension between the solid and liquid phases. The idea that the origin of flux residue is wettability between flux melts and garnet surfaces is supported by the following experimental result. [16]

Figures $11 \mathrm{a}, 11 \mathrm{~b}$ and $11 \mathrm{c}$ show how the mode of flux residue on LPE garnet films of $(\mathrm{LuBi})_{3} \mathrm{Fe}_{5} \mathrm{O}_{12}$ grown from the $\mathrm{PbO}-\mathrm{Bi}_{2} \mathrm{O}_{3}$ flux melt at $745^{\circ} \mathrm{C}$ differs, depending on the wafer orientation. Even after spinning off the flux on the wafer at $428 \mathrm{rpm}$, the flux residue was found to cover the entire wafer surface of the $\{100\}$ film and a portion at the center of the $\{111\}$ film. For the $\{110\}$ film, the flux did not remain on the wafer surface except for a few small droplets. For the flux residue on the $\{100\}$ and $\{111\}$ films, a spreading type of wetting took place; the contact angle is $0^{\circ}$. On the other hand, droplets on the $\{110\}$ wafer suggests an adhesion type of wetting; the contact angle is $>0^{\circ}$. Large wettability for $\{100\}$ wafers would be explained by a small interfacial tension for this orientation. Spreading type wetting was not observed between $\{111\}$ LPE films and $\mathrm{PbO}-\mathrm{B}_{2} \mathrm{O}_{3}$ flux melt but it easily takes place for $\mathrm{Bi}_{2} \mathrm{O}_{3}$-containing flux melts. Flux residue was observed even for $\{110\}$ films grown from $\mathrm{PbO}-\mathrm{Bi}_{2} \mathrm{O}_{3}-\mathrm{B}_{2} \mathrm{O}_{3}$ flux, although $\{110\}$ has the highest order of morphological importance according to $\mathrm{PBC}$ analysis. [17]

Since the surface is polished to adjust the thickness of wafers, where $45^{\circ}$ Faraday rotation of polarization of incident light takes place, flux residue for Bi-substituted garnet films is not a big problem from the viewpoint of practical application.

\section{IMPURITY INCORPORATION AND OPTICAL ABSORPTION}

Control of optical absorption of garnet films is of high priority for optical device applications. For an optical isolator, a figure of merit as large as over $75 \% \mathrm{~dB}$ is required. Although iron garnets are transparent in the wavelength region from 1.0 to $5.0 \mu \mathrm{m},[18]$ the valence change of $\mathrm{Fe}^{3+}$ into $\mathrm{Fe}^{2+}$ or $\mathrm{Fe}^{4+}$ causes an increase in optical absorption, as reported by Wood and Remeika. [19] Efforts should be made to avoid incorporation of impurities which causes the above mentioned valence change of $\mathrm{Fe}^{3+}$, such as $\mathrm{Pb}^{2+}, \mathrm{Pb}^{4+}$ and $\mathrm{Pt}^{4+} ; \mathrm{Pb}^{2+}$ and $\mathrm{Pb}^{4+}$ ions are from the $\mathrm{PbO}-\mathrm{B}_{2} \mathrm{O}_{3}$ flux melt and $\mathrm{Pt}_{4}+$ from a platinum crucible through corrosion by a flux melt. [20]

By following the process to obtain lowered optical absorption, growth condition dependence of optical absorption was carefully examined. [21] As shown in Fig.12, optical absorption coefficients increased with increasing supercooling temperature for all the melts examined. This implies that as small supercooling as possible is required to obtain LPE films with small optical absorption. For $\mathrm{Gd}_{0.2} \mathrm{Y}_{2.8} \mathrm{Fe}_{5} \mathrm{O}_{12}$ films a minimum optical absorption coefficient of $0.2 \mathrm{~cm}^{-1}$ was observed; this value corresponds to figure of merit of $230 \% \mathrm{~dB}$, since the $\mathrm{Gd}_{0.2} \mathrm{Y}_{2.8} \mathrm{Fe}_{5} \mathrm{O}_{12}$ film has a Faraday rotation coefficient of $200 \mathrm{deg} / \mathrm{cm}$ at $1.3 \mu \mathrm{m}$.

Growth orientation also affects optical absorption. Figure 13 shows a growth rate dependence of optical absorption coefficients for LPE $\mathrm{Gd}_{0.2} \mathrm{Y}_{2.8} \mathrm{Fe}_{5} \mathrm{O}_{12}$ films grown isothermally $\left(933 \pm 1.3^{\circ} \mathrm{C}\right)$ on $\mathrm{GGG}$ substrates, where growth rate was varied by changing both substrate rotation speed and growth orientation. Optical absorptions for $\{110\}$ and $\{211\}$ films were not measured, since prism contact was not attained due to hillock formation on these crystallographic planes. For reference, optical absorption values measured for the

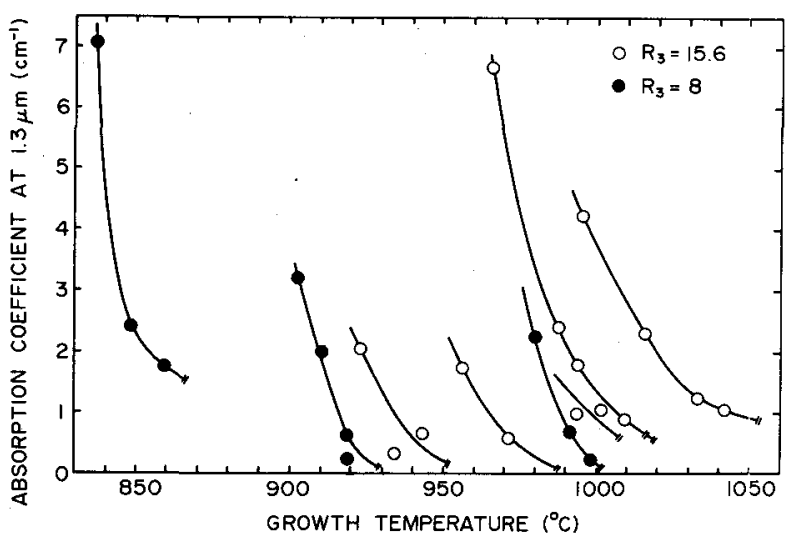

Fig.12. Optical absorption coeffcient $\alpha$ as a function of growth temperature for LPE $\mathrm{Gd}_{0.2} \mathrm{Y}_{2.8} \mathrm{Fe}_{5} \mathrm{O}_{12}$ films grown from melts with various liquidus temperatures. [20]

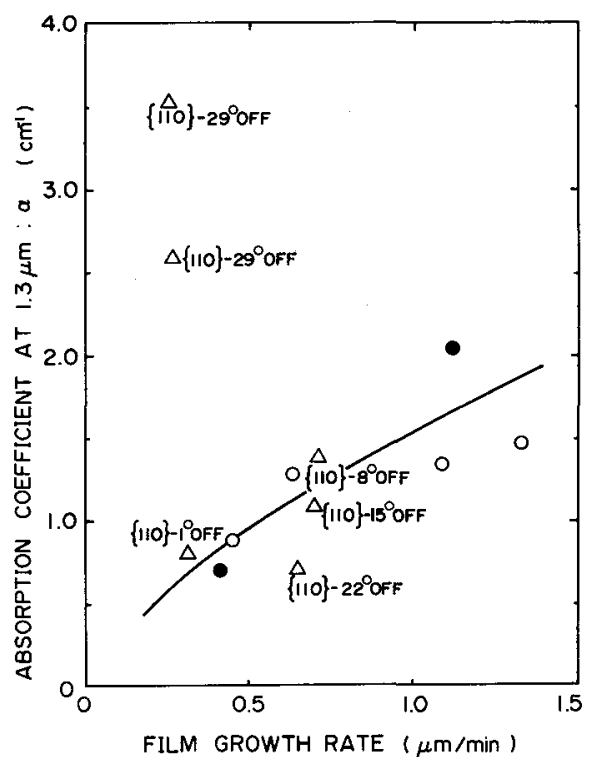

Fig.13. Optical absorption coefficient as a function of film growth rate: growth rate was varied isothermally by changing substrate rotation speed $(O)$ and growth orientation $(\Delta): 933 \pm 1.3^{\circ} \mathrm{C}$. Growth rate was also varied by changing supercooling temperature (0). [20] 
films grown at various growth rate were also superimposed, where growth rate was changed by changing the degree of melt supercooling. As clearly shown in Fig. 13, the optical absorption coefficient a increased with the increase in growth rate, regardless of the means of changing growth rate. Since the minimum optical absorption was obtained for the films whose growth rate was $0 \mu \mathrm{m} / \mathrm{min}$, the increase in optical absorption is due to a kinetic effect during LPE growth, which enhances the incorporation of impurity ions, such as $\mathrm{Pb}^{2+}$, $\mathrm{Pb}^{4+}$ and $\mathrm{Pt}^{4+}$. [22] An Increase in growth rate through an increase in supercooling temperature and in substrate rotation speed, and choice of substrate orientation results in an increased distribution coefficient of impurity ions whose values are less than unity, as follows:[23]

$$
k=k_{0} /\left[k_{0}+\left(1-k_{0}\right) \exp (-v \delta / D)\right]
$$

where $k_{0}$ and $k$ are equilibrium and effective distribution coefficients of impurities. $v$ is the growth rate, $\delta$ the thickness of a diffusion boundary layer, $\mathrm{D}$ a diffusion constant of impurity. The anomalous increase in optical absorption for the film grown on the $\{110\}-29^{\circ}$ off, that is $\{211\}-1^{\circ}$ off substrate, is due to enhanced $\mathrm{Pb}$ incorporation on this crystallographic plane during LPE growth. [7] As shown in Fig. 9, the growth rate for the $\{211\}$ was found to be faster than that for the $\{110\}$. The step front displacement velocity for the $\{211\}$ would be also faster than that for the $\{110\}$ and would cause easy $\mathrm{Pb}$ incorporation, although both the $\{110\}$ and $\{211\}$ are "flat" surfaces for the garnet system, and have a smaller growth rate than the $\{111\}$ which is a "rough" surface for the garnet system and has the fastest growth rate.

For application of LPE garnet films to magneto-optic devices for use in 1.3 and $1.5 \mu \mathrm{m}$ bands, as-grown films can be utilized. However, for application in the $0.8 \mathrm{\mu m}$ band, optical absorption is still too large and aftergrowth treatments have been attempted by several workers: annealing or chemical reduction of $\mathrm{Fe}^{4+}$ by hydrazine or hydrogen. [24-26] A figure of merit of $30 \% \mathrm{~dB}$ at $0.79 \mu \mathrm{m}$ was attained by hydrazine reduction, [25] and $27 \% \mathrm{~dB}$ by annealing. [26]

\section{CONCLUSION}

For growth of LPE garnet films over $300 \mu \mathrm{m}$ thick, it is essential to fully utilize the merits of epitaxial growth and to minimize the demerits due to "bulk-like" behavior during growth. For LPE growth, \{111\} growth, which does not take place for bulk crystal growth by a flux method, is available and assures over 300 $\mu \mathrm{m}$ thick, inclusion-free and transparent films with an almost flat surface. As for optical absorption in the $0.8 \mu \mathrm{m}$ band, further efforts are necessary to obtain transparent garnet films.

\section{REFERENCES}

1. T. Aoyama, K. Doi, H. Uchida, T. Hibiya, Y. Ohta and K. Matsumi: 7th European Conference on Optical Communications, Copenhagen,Denmark, September 1981.

2. T. Aoyama: 8th Conference on Optical Fiber Communication, San Diego, February 1985.

3. T. Hibiya: J. Crystal Growth 64 (1983) 499.

4. S. L. Blank and J. W. Nielsen: J. Crystal Growth 17 (1972) 302.

5. N. Kimizuka and T. Katsura: J. Solid State Chem. 13 (1975) 176.

6. T. Aoyama, T. Hibiya, Y. Ohta and K. Matsumi: NEC RESEARCH \& DEVELOPMENT No.66,(1982), p.44.

7. T. Hibiya: J. Crystal Growth 62 (1983) 87.

8. T. Hibiya: J. Crystal Growth 64 (1983) 400.

9. K. Yamaguchi, N. Kono, K. Asama, H. Inoue and T. Mori: J. Appl. Phys. 49 (1978) 1968.

10. Y.Asahara, Y. Nomi and K. Machida: 38th Symposium Papers, 38-10, Hamana-ko, Jpn. 1985

11. T. Ishikawa, T. Hibiya, K. Ono and K. Shiroki: J. Mag. Soc. Jpn. 10 (1986) 147.

12. T. Hibiya, T. Ishikawa, Y. Morishige, J. Nakashima and Y. Ohta: NEC RESEARCH \& DEVELOPMENT No. 80,(1986), p. 1 .

13. T. R. Johansen, F. G. Hewitt, E. J. Torok and D. L. Fleming: AIP Conf. Proc. No.29, (1976) 580.

14. C. -P. Klages and W. Tolksdorf: J. Crystal Growth64 (1983) 275.

15. A. W. Adamson: "Physical Chemistry of Surface, 4th ed." Wiley, New York (1982).

16. T. Hibiya and O. Okada: J. Crystal Growth 67 (1984) 566.

17. P. Bennema, E. A. Giess and J. E. Weidenborner: J. Crystal Growth 62 (1983) 41.

18. J. F. Dillon: Bull. Amer. Phys. Soc. [II] 2 (1957) 238.

19. D. L. Wood and J. P. Remeika: J. Appl. Phys. 38 (1967) 1038.

20. H. L. Glass and M. T. Elliott: J. crystal Growth 27 (1974) 253.

21. T. Hibiya and J. Nakajima: J. Appl. Phys. 54 (1983) 7110.

22. J. M. Robertson, M. J. van Hout, J. C. Verplanke and J. C. Brice, Mater. Res. Bull. 9 (1974) 555.

23. J. A. Burton, R. C. Prim and W. P. Slichter: J. Chem. Phys. 21 (1953) 1987.

24. M. Kaneko, T. Okamoto, H. Tamada and T. Yamada: J. Magn. Soc. Jpn. 10 (1986) 161.

25. Y. Yokoyama, T. Takahashi and N. Koshizuka: J. Magn. Soc. Jpn. 10 (1986) 165.

26. T. Ishikawa, K. Ono and K. Shiroki: International Symposium on Magneto-Optics 1987, Kyoto, Japan. 